\title{
Benign lymphoepithelial cysts of the parotid: long-term surgical results
}

This article was published in the following Dove Press journal:

HIVIAIDS - Research and Palliative Care

26 May 2012

Number of times this article has been viewed

\author{
Matthew K Steehler' \\ Mark W Steehler ${ }^{2-4}$ \\ Steven $\mathrm{P}$ Davison ${ }^{1,5}$ \\ 'Georgetown University Hospital \\ Department of Otolaryngology \\ Head and Neck surgery, Washington, \\ DC, USA ; ${ }^{2}$ Lake Erie Consortium \\ for Osteopathic Medical Training, \\ ${ }^{3}$ Millcreek Community Hospital, \\ ${ }^{4}$ Ear Nose and Throat Surgeons \\ of Northwest Pennsylvania, Erie, \\ PA, USA; ${ }^{5}$ DAVinci Plastic Surgery, \\ Washington, DC, USA
}

\begin{abstract}
Benign lymphoepithelial cysts are a widely recognized cause of parotid gland swelling in patients infected with the human immunodeficiency virus (HIV). These cysts are pathognomonic for HIV. The cysts frequently grow to be exceptionally large, causing physical deformity and gross asymmetry of facial contour. This clinical commentary analyzes this cosmetically deforming disease entity and the many treatments that accompany it. The patient presented in this paper is a surgical case-control. The case is a microcosm for our findings upon review of the literature. Treatment options for benign lymphoepithelial cysts include repeated fine-needle aspiration and drainage, surgery, radiotherapy, sclerotherapy, and conservative therapy, with institution of highly active antiretroviral therapy medication. Based on this surgical case-control and our review of the literature, it is concluded that surgical intervention offers the best cosmetic result for these patients.
\end{abstract}

Keywords: parotid, benign lymphoepithelial cyst, parotidectomy, human immunodeficiency virus, head and neck surgery, cosmetic surgery

\section{Introduction}

A 32-year-old female with human immunodeficiency virus (HIV) infection presented to our office six years after we had performed a right superficial parotidectomy for a $10 \mathrm{~cm} \times 8 \mathrm{~cm}$ benign lymphoepithelial cyst (BLEC). This was cured surgically with excellent cosmetic outcome. The patient presented at this time with a similarly large lesion on the contralateral side which was removed in a similar fashion (see Figure 1). The patient tolerated the procedure well with no postoperative morbidity, normal facial nerve function, and a well healed scar.

The 6-year follow-up on this patient represents a case control study demonstrating the efficacy of parotidectomy in the treatment of BLEC. The only indication for removal of BLEC is when there is an expanding lesion distorting the patient's facial appearance. In order to delve further into the best treatment for this cosmetic problem, a Medline search and review of the literature on BLEC was performed. To the best of the authors' knowledge, this paper is the first to review the etiology, diagnosis, and treatment options for BLEC.

Stendence: Matthew K Steehler Department of Otolaryngology, Head and Neck Surgery, Georgetown University Hospital, Ist Floor Gorman Building, 3800 Reservoir Drive, Washington, DC 20007, USA

$\mathrm{Tel}+\mathrm{I} 8 \mathrm{I} 44500742$

Fax + I 202444 I3 I2

Email mattsteehler@yahoo.com

\section{Literature review}

Benign lymphoepithelial cysts (BLECs) are a widely recognized cause of parotid gland swelling in HIV-infected patients. Although they are neither invasive nor associated with malignant degeneration, BLECs can become large and disfiguring. 


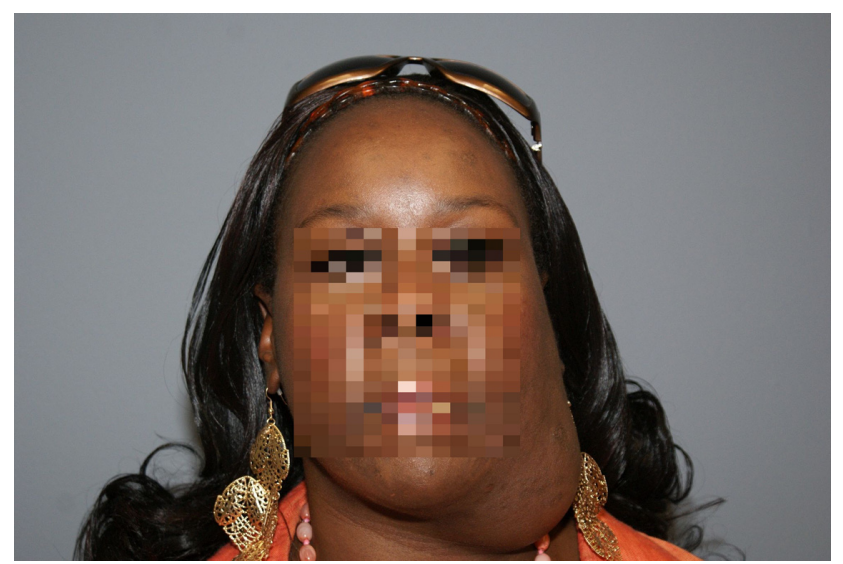

Figure I Patient with HIV BLEC of the left parotid gland.

Notes: Patient is status postsuperficial parotidectomy on the right side 6 years ago (complete resolution). Patient routinely wears multiple accessories daily to distract others from her obvious facial lesion (32-year-old patient, May 20I0).

Abbreviation: BLEC, benign lymphoepithelial cyst.

These lesions can be a cosmetically devastating physical deformity, causing isolation and depression. ${ }^{1-6}$ They are easily recognized as a manifestation of HIV in the aware population.

BLEC of the parotid gland is the most common salivary gland pathology in HIV., ${ }^{1,2}$ BLEC has two hypothesized etiologic mechanisms. The first theorized pathogenesis of BLEC is the "obstructive theory" which states that lymphoid proliferation in the parotid gland leads to ductal obstruction and salivary dilation that mimics a true cyst. ${ }^{1,3,4,7-9}$ The second hypothesized theory is that HIV-related reactive lymphoproliferation occurs in the lymph nodes of the parotid gland. The parotid glandular epithelium becomes trapped in normal intraparotid lymph nodes, resulting in cystic enlargement. ${ }^{1,7,8}$

Diagnosis of BLEC is made based on history, physical examination, and fine-needle aspiration biopsy. BLEC is nearly diagnostic for HIV., ${ }^{1,2}$ Physical examination will show obvious fluctuant cystic facial deformity. Fine-needle aspiration biopsy of BLEC results in clear, proteinaceous (straw-colored) fluid, with a mixture of epithelial (squamous) and benign lymphoid cells. ${ }^{7}, 10$ This combination of history, physical examination, and fine-needle aspiration biopsy is diagnostic for BLEC. ${ }^{3,10}$

Treatment of this particular pathology has been widely debated in the literature. Previous treatments for BLEC have included repeated fine-needle aspiration and drainage, surgery, radiotherapy, sclerotherapy, and conservative therapy with institution of highly active antiretroviral therapy (HAART) medications..$^{2-6,10-22}$ Table 1 summarizes the advantages and disadvantages, duration of procedures,

Table I Advantages and disadvantages of treatment for benign lymphoepithelial cysts of the parotid gland as well as treatment duration and cost of treatment

\begin{tabular}{|c|c|c|c|c|}
\hline & Advantages & Disadvantages & $\begin{array}{l}\text { Length of } \\
\text { treatment }\end{array}$ & $\begin{array}{l}\text { Estimated cost of } \\
\text { treatment }\end{array}$ \\
\hline HAART therapy & $\begin{array}{l}\text { - Noninvasive } \\
\text { - Standard of care for HIV } \\
\text { - Partial response }\end{array}$ & - Incomplete response & $\geq 3$ months & $\$ 1250 /$ month \\
\hline FNA drainage & $\begin{array}{l}\text { - Minimally invasive } \\
\text { - Avoids radiation }\end{array}$ & $\begin{array}{l}\text { - } 100 \% \text { recurrence rate } \\
\text { - Multiple treatments }\end{array}$ & $\leq 2 \times /$ month & $\$ 450 /$ procedure \\
\hline Radiation therapy & $\begin{array}{l}\text { - Noninvasive } \\
\text { - Avoids needle stick injuries }\end{array}$ & $\begin{array}{l}\text { - Therapeutic doses of radiation (24 Gray) } \\
\text { - Side effects include xerostomia, } \\
\text { skin necrosis, mucositis } \\
\text { - Incomplete response }\end{array}$ & 3 weeks & $\$ 17,600$ total \\
\hline Sclerotherapy & $\begin{array}{l}\text { - Minimally invasive } \\
\text { - Avoids radiation }\end{array}$ & $\begin{array}{l}\text { - Multiple treatments } \\
\text { - Varying degrees of drug toxicities ranging } \\
\text { from rash to pulmonary fibrosis } \\
\text { - Incomplete response } \\
\text { - Fibrosis makes future surgery more difficult }\end{array}$ & I-4 procedures & $\begin{array}{l}\$ 450 / \text { procedure } \\
\text { Bleomycin, } \$ 1450 / \\
\text { procedure } \\
\text { OK-432, orphan drug, } \\
\text { not approved by the } \\
\text { FDA in the US }\end{array}$ \\
\hline Surgery & $\begin{array}{l}\text { - Complete response } \\
\text { - Cosmetically superior } \\
\text { - Avoids radiation }\end{array}$ & $\begin{array}{l}\text { - General anesthesia } \\
\text { - } 23 \text {-hour observational stay in hospital } \\
\text { - } 2-6 \text {-hour invasive procedure } \\
\text { - Surgical scar } \\
\text { - Surgical complications hematoma }(7 \%) \text {, } \\
\text { facial nerve injury }(2.3 \%-6 \%) \text {, Frey's } \\
\text { syndrome }(5 \%) \text {, recurrence }(2 \%)^{15,16,26,27}\end{array}$ & One surgery & $\$ 8000$ total \\
\hline
\end{tabular}

Abbreviations: FNA, fine-needle aspiration; HAART, highly active antiretroviral therapy; HIV, human immunodeficiency virus. 


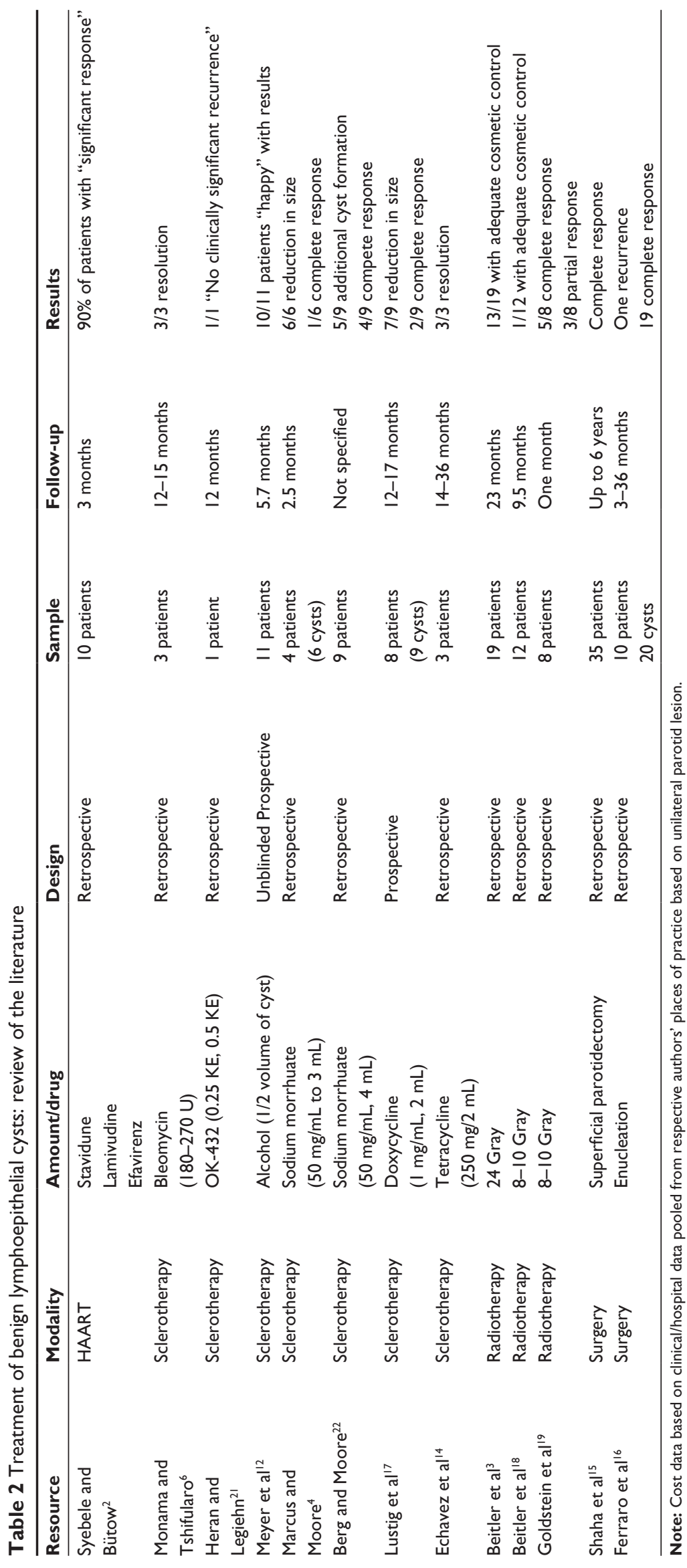


and the cost of treatment for BLEC. A literature review of the aforementioned treatments for BLEC is summarized in the remainder of this paper and in Table 2.

\section{HAART}

Instituting HAART for BLEC has been shown to be effective in decreasing the size of the lesions. ${ }^{2,7}$ HAART treats systemic HIV by inhibiting retroviral transcription and viral replication. HAART therapy is theorized to correct the root cause of BLEC, ie, HIV infection. In a study by Syebele and Bütow, nine of ten patients with BLEC were found to have "a significant decrease in cyst size" (which was not quantified) after institution of HAART. ${ }^{2}$ Cysts were still present at completion of the study. medications instituted in the study included two nucleoside analog reverse transcriptase inhibitors (stavudine and lamivudine) and one non-nucleoside reverse transcriptase inhibitor (efavirenz). ${ }^{2}$

\section{Fine-needle aspiration and drainage}

Repeated fine-needle aspiration and drainage is a popular treatment for BLEC. The first aspiration typically occurs in the setting of the fine-needle aspiration biopsy, which rules out the possibility of another pathologic condition. Cysts can be drained up to twice per month, but there is a $100 \%$ recurrence rate in spite of this treatment. ${ }^{15,16,20}$

\section{Radiation therapy}

In 1995, 12 patients with BLEC were given 8-10 Gray of radiation therapy. Although initial results were encouraging, longer follow-up revealed that only one of 12 patients had adequate cosmetic control at 9.5 months. ${ }^{18}$ Worse, after initial failure, retreatment of eight patients with 8-10 Gray produced fewer responses and no long-term local control. ${ }^{18}$ In 1999, Beitler et al studied 20 patients with BLEC, each treated with 18-24 Gray of radiation therapy to the parotid glands. ${ }^{3}$ They were able to demonstrate partial cosmetic control of the disease in 14 of 20 patients. Side effects of treatment included xerostomia and mucositis. ${ }^{3}$

\section{Sclerotherapy}

Sclerotherapy injections for BLEC includes multiple sclerotic agents, eg, sodium morrhuate, doxycycline, ethanol, bleomycin, and OK-432.4,6,12,13,21 The studies on ethanol only evaluated patients subjectively as being pleased or displeased with their results, and therefore will not be discussed. ${ }^{12}$ Doxycycline injection into the cysts resulted in a $22 \%$ (2/9 cysts) complete response rate. ${ }^{22}$ Two of the patients in the doxycycline treatment group opted for superficial parotidectomy as definitive treatment for their cysts. ${ }^{13}$ In two studies evaluating sodium morrhuate sclerotherapy, injections resulted in $17 \%(1 / 6$ cysts) and 44\% (4/9) complete response rates, respectively. ${ }^{4,9}$ Although limited in patient population size, sclerotherapy with bleomycin resulted in completed resolution in $3 / 3$ patients $(100 \%)$ with no side effects (although it has been noted to cause life-threatening irreversible pulmonary fibrosis when given as chemotherapy). ${ }^{6} \mathrm{OK}-432$ (picibanil) has been strongly advocated as the treatment of choice for macrocystic lymphatic malformations. ${ }^{23}$ Although BLEC is a different pathologic entity from cystic hygroma, there has been one reported case of BLEC that was satisfactorily treated with OK-432. Heran and Legiehn reported on multiple injections of OK-432 performed in one patient over the course of three months. The patient initially had the common side effects of low-grade fever and local swelling/erythema at the injection site, but these were self-limiting and resolved after one month. At one-year follow-up, the patient had no significant clinical recurrence. ${ }^{21}$ Of note, this study was not published in a peer-reviewed journal, but was presented in its entirety at the 2009 meeting of the Cardiovascular and Interventional Radiological Society of Europe in Lisbon, Portugal. ${ }^{21}$

\section{Surgery}

The initial studies regarding BLEC and surgery were performed in the early 1990s. Shaha et al undertook a retrospective review of 35 parotidectomies (20 superficial parotidectomies, 15 removal of the parotid tail for isolated cysts) for BLEC with up to six years of follow-up. ${ }^{15}$ A complete response was seen in all 35 patients, although cysts did develop on the contralateral side in several patients. A study by Ferraro et al looked at surgical enucleation of 10 patients with bilateral BLEC (20

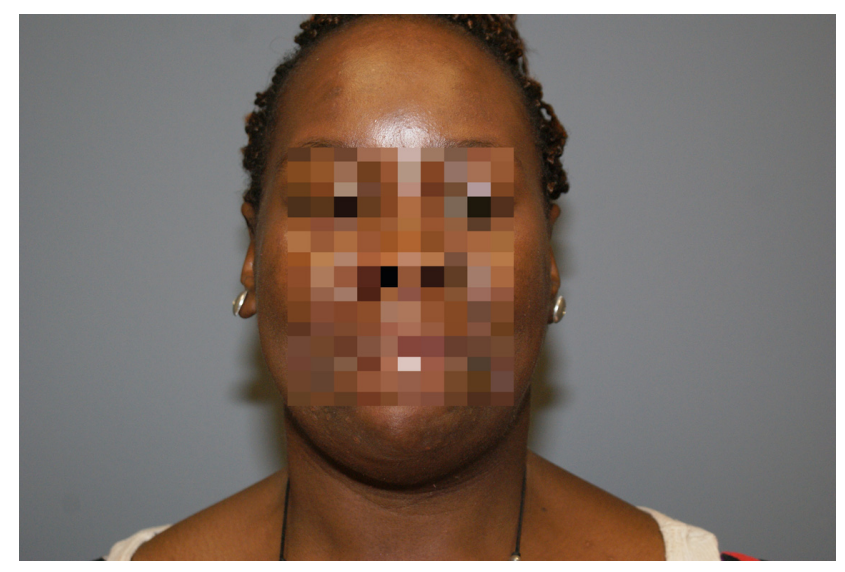

Figure 2 Patient 6 weeks postoperatively after left superficial parotidectomy. A similar result can be seen as compared to the right side. Facial contour and symmetry has been restored with excellent cosmetic outcome. 
cysts total). Follow-up ranged from 3 to 36 months, with 19 complete responses and one recurrence. ${ }^{16}$

\section{Discussion}

The indication for treatment of BLEC is cosmetic. As stated earlier, this pathology can be a cosmetically devastating physical deformity, causing social isolation and depression. ${ }^{1-6}$ The treatment that provides the best cosmetic outcome should be the treatment of choice. All treatments for BLEC show a partial response, but the only treatment to show a complete response in this pathology consistently with no recurrence is surgical intervention. Although bleomycin and OK-432 sclerotherapy injections have shown promising results, the data are currently limited to a case series (bleomycin, three patients) and a case report (OK-432). Limited data on the aforementioned therapies are available because these pilot studies were only recently performed. There is a need for further clinical data to support the use of bleomycin and OK-432 sclerosants in the treatment of BLEC. The side effect profile of OK-432 is mostly inflammatory in nature, with the major side effect being airway obstruction in patients treated for lymphatic malformations. ${ }^{23}$ Fatal side effects have been associated with bleomycin in the form of irreversible pulmonary fibrosis. ${ }^{23}$ In addition, the majority of BLECs are multiloculated, making injections into each loculation on multiple occasions challenging, time-consuming, and often unsuccessful. In 2009, Smith et al reported no response to treatment with OK-432 in 17 cases of microcystic multiloculated lymphatic malformations. ${ }^{23}$ The last potential pitfall of sclerotherapy is that these agents aim to scar the particular area of injection to cause obliteration. If sclerotherapy is unsuccessful, then surgical intervention for cure is more difficult in the setting of scarring and sclerosis. The doxycycline study by Lustig et $\mathrm{al}^{17}$ shows how failures of sclerotherapy must resort to surgical intervention for definitive treatment ( 2 patients). The scarring caused by sclerotherapy could cause more postsurgical morbidity in the setting of a scarred operative field (eg, facial nerve injury).

Reservations regarding parotidectomy in HIV-infected patients include the following: immunocompromised patients have a higher rate of postoperative infections, there is an unnecessary risk of HIV transmission imposed on the surgeon and the surgical team, and there could be facial nerve injury. Recent studies show that the postoperative rate of infection in HIV-infected patients is similar to that in the normal population, and is likely due to advances in the treatment of this disease. ${ }^{24}$ New drug regimens for the medical treatment of
HIV patients in the perioperative period have been developed, and with the advent of viral load measurement, the risks of HIV transmission during surgery have been dramatically reduced.$^{25}$ Regarding the complications of parotidectomy in the treatment of BLEC, surgical intervention has been compared with routine superficial parotidectomy for pleomorphic adenoma. ${ }^{26}$ In the hands of an experienced surgeon, parotid gland surgery for benign disease has been shown to have a permanent paresis rate of $2.3 \%$ (one or more branches of the facial nerve), while partial superficial parotidectomy has a permanent paresis rate of $0 \%$ (Table 2) ${ }^{26,27}$

There are two other issues that must be addressed regarding surgical intervention. The prognosis of HIV has changed markedly in the past 30 years. From 1981 to 1996, the disease had a dismal prognosis, but since the establishment of HAART therapy in 1996, HIV has become a chronic disease with an excellent prognosis. ${ }^{28}$ Given the success of surgery in BLEC, the argument for surgical intervention is further strengthened by the improved health and longevity of HIV-infected patients. The second issue regarding surgical intervention is that some surgeons believe that the surgical defect caused by removal of these large cysts will cause a substantial cosmetically deforming indentation. Parotidectomy defects can be cosmetically reconstructed in a variety of ways, including use of a cadaveric dermal matrix $\left(\right.$ Alloderm $\left.^{\circledR}\right)$, abdominal fat grafts, sternocleidomastoid muscle flaps, de-epithelialized radial forearm free flaps, and rectus abdominus free flaps. ${ }^{29}$ In the case presented here, a cervical rotation flap with placement of Alloderm was performed to correct the patient's left-sided parotid defect. In order to avoid donor site morbidity, the authors decided that Alloderm was the best reconstructive option for this patient. At 6 weeks postoperatively, the patient was doing well, with excellent facial symmetry (Figure 2).

The case presented here illustrates excellent postsurgical control of BLEC after 6 years and demonstrates the disease course of untreated progression on the contralateral side. This patient represents an unblinded surgical case-control which demonstrates the efficacy of surgery for this condition.

\section{Conclusion}

There are many suboptimal cosmetic therapies used in the treatment of BLEC. Surgery is the gold standard treatment for BLEC, as evidenced by this literature review and case example.

\section{Disclosure}

The authors report no conflicts of interest in this work. 


\section{References}

1. Shanti RM, Aziz SR. HIV-associated salivary gland disease. Oral Maxillofac Surg Clin North Am. 2009;21:339-343.

2. Syebele K, Bütow KW. Comparative study of the effect of antiretroviral therapy on benign lymphoepithelial cyst of parotid glands and ranulas in HIV-positive patients. Oral Surg Oral Med Oral Pathol Oral Radiol Endod. 2011;111:205-210.

3. Beitler JJ, Vikram B, Silver CE, et al. Low dose radiotherapy for multicystic benign lymphoepithelial lesions of the parotid gland in HIVpositive patients: Long-term results. Head Neck. 1995;17:31-35.

4. Marcus A, Moore CE. Sodium morrhuate sclerotherapy for treatment of benign lymphoepithelial cysts of parotid gland in an HIV patient. Laryngoscope. 2005;4:746-749.

5. Michelow P, Dezube BJ, Pantanowitz L. Fine needle aspiration of salivary gland masses in HIV-infected patients. Diagn Cytopathol. January 6, 2011. [Epub ahead of print.]

6. Monama GM, Tshifularo MI. Intralesional bleomycin injections in the treatment of benign lymphoepithelial cysts of the parotid gland in HIV-positive patients: case reports. Laryngoscope. 2010;120: 243-246.

7. Wu L, Cheng J, Maruyama S, et al. Lymphoepithelial cyst of the parotid gland: its possible histopathogenesis based on clinicopathologic analysis of 64 cases. Hum Pathol. 2009;40:683-692.

8. Malorano E, Favia G, Viale G. Lymphoepithelial cysts of salivary glands: an immunohistochemical study of HIV-related and HIVunrelated lesions. Hum Pathol. 1998;29:260-265.

9. Mandel L, Surattanont F. Regression of HIV parotid swellings after antiviral therapy: case reports with computed tomographic scan evidence. Oral Surg Oral Med Oral Pathol Oral Radiol Endod. 2002;94:454-459.

10. Witt RL. Salivary Gland Diseases: Surgical and Medical Management. New York, NY: Thieme Publishing; 2005.

11. Syebele K. Regression of both oral mucocele and parotid swellings, following antiretroviral therapy. Int J Pediatr Otorhinolaryngol. 2010;74:89-92.

12. Meyer E, Lubbe DE, Fagan JJ. Alcohol sclerotherapy of human immunodeficiency virus related parotid lymphoepithelial cysts. J Laryngol Otol. 2009;123:422-425.

13. Suskind DL, Tavill MA, Handler SD. Doxycycline sclerotherapy of benign lymphoepithelial cysts of the parotid: a minimally invasive treatment. Int J Pediatr Otorhinolaryngol. 2000;52:157-161.

14. Echavez MI, Lee KC, Sooy CD. Tetracycline sclerosis for treatment of benign lymphoepithelial cysts of the parotid gland in patients infected with human immunodeficiency virus. Laryngoscope. 1994;104:1499-1502.
15. Shaha AR, DiMaio T, Webber C, Thelmo W, Jaffe BM. Benign lymphoepithelial lesions of the parotid. Am J Surg. 1993;166: 403-406.

16. Ferraro FJ Jr, Rush BF Jr, Ruark D, Oleske J. Enucleation of parotid lymphoepithelial cyst in patients who are human immunodeficiency virus positive. Surg Gynecol Obstet. 1993;177:524-526.

17. Lustig LR, Lee KC, Murr A, et al. Doxycycline sclerosis of benign lymphoepithelial cysts in patients infected with HIV. Laryngoscope. 1998;108:1199-1205.

18. Beitler JJ, Smith RV, Brook A, et al. Benign parotid hypertrophy in HIV+ patients: limited late failures after external radiation. Int J Radiat Oncol Biol Phys. 1999;45:451-455.

19. Goldstein J, Rubin J, Silver C, et al. Radiation therapy as a treatment for benign lymphoepithelial parotid cysts in patients infected with human immunodeficiency virus-1. Int $J$ Radiat Oncol Biol Phys. 1992;23:1045-1050.

20. Terry JH, Loree TR, Thomas MD, et al. Major salivary gland lymphoepithelial lesions and the acquired immunodeficiency syndrome. Am J Surg. 1991;162:324-329.

21. Heran MKS, Legiehn GM. OK-432 sclerotherapy of parotid lymphoepithelial cysts in an HIV patient. Poster presented at the Cardiovascular and Interventional Radiological Society of Europe meeting, September 19-23, 2009. Lisbon, Portugal.

22. Berg EE, Moore CE. Office-based sclerotherapy for benign parotid lymphoepithelial cysts in the HIV-positive patient. Laryngoscope. 2009;119:868-870.

23. Smith MC, Zimmerman MB, Burke DK, et al. Efficacy and safety of OK-432 immunotherapy of lymphatic malformations. Laryngoscope. 2009;119:107-115.

24. Cavasin H, Dola T, Uribe O, et al. Postoperative infectious morbidities of cesarean delivery in human immunodeficiency virus-infected women. Infect Dis Obstet Gynecol. May 25, 2009. [Epub ahead of print.]

25. Papendorp SG, van den Berk GE. Preoperative use of raltegravircontaining regimen as induction therapy: very rapid decline of HIV-1 viral load. AIDS. 2010;24:1603-1608.

26. Koch M, Zenk J, Iro H. Long-term results of morbidity after parotid gland surgery in benign disease. Laryngoscope. 2010;120:724-730.

27. Guntinas-Lichius O, Klussmann JP, Wittekindt C, Stennert E. Parotidectomy for benign parotid disease at a university teaching hospital: outcome of 963 operations. Laryngoscope. 2006;116(4):534-540.

28. Lisette O, Mansi S, Rovini H. HIV combination products. Nat Rev Drug Discov. 2007;6:951-952.

29. Ghanem T. Parotid defects. Facial Plast Surg Clin North Am. 2009;17:263-269.
HIV/AIDS - Research and Palliative Care

\section{Publish your work in this journal}

HIV/AIDS - Research and Palliative Care is an international, peerreviewed open-access journal focusing on advances in research in HIV, its clinical progression and management options including antiviral treatment, palliative care and public healthcare policies to control viral spread. The journal welcomes original research, basic science,

\section{Dovepress}

clinical \& epidemiological studies, reviews \& evaluations, expert opinion \& commentary, case reports \& extended reports. The manuscript management system is completely online and includes a very quick and fair peer-review system. Visit http://www.dovepress.com/ testimonials.php to read real quotes from published authors. 